\title{
Staged Venture Capital Investment considering Unexpected Major Events
}

\author{
Yindong Zhang, Kaili Xiang, Chuan Ding, and Tao Chen \\ School of Economics and Mathematics, Southwestern University of Finance and Economics, Chengdu, China \\ Correspondence should be addressed to Yindong Zhang; 214580176@qq.com
}

Received 16 January 2017; Accepted 22 February 2017; Published 12 March 2017

Academic Editor: Lu Zhen

Copyright (c) 2017 Yindong Zhang et al. This is an open access article distributed under the Creative Commons Attribution License, which permits unrestricted use, distribution, and reproduction in any medium, provided the original work is properly cited.

\begin{abstract}
This paper presents a dynamic model of capital financing, taking into consideration unexpected major events occurring within continuous time model. We are considering a special jump-diffusion model first described by Samuelson (1973) while using traditional geometric Brownian motion. This paper seeks to accurately show the innovative project valuation when unexpected major events occur and get the analytical results of the project option value. Furthermore, we analyzed the impact of multistaged financing; results indicated that both sources of uncertainty positively impact the project option value; particularly, the option price when considering unexpected major events occurrence is larger than the option price without unexpected major events. Based on a comparative-static analysis, new propositions for optimal amount of investment and optimal level of project are derived from simulations.
\end{abstract}

\section{Introduction}

With the acceleration of technology improvement and economic globalization, more and more entrepreneurs (EN) focus on the implementation of innovative investment projects, which could not translate into commercialization without a large scale financial support. It could be very difficult or almost impossible to receive finance service support from traditional channels such as banks and securities agencies for entrepreneurs due to the shaky nature of innovative projects, incompleteness of accounting certificates, or insufficiency of fixed assets. With regard to these implied characteristics, venture capital (VC) has become a significant source of financing for entrepreneurs under capital constraint. VCs provide not only capital venture funds to the EN, but also assistance with strategic and operational planning, management recruitment, marketing, and obtaining additional capital, for the purpose of promoting the level of profitableness by acquisition or IPO. The venture capital industry has grown dramatically over the last decade. According to the KPMG and CB Insights, the amount of capital investment totaled 27.4 billion in the second quarter and 53.9 billion in the first half year of 2016, which is due to 3894 cases all over the world, indicating the importance of VC-financing for sustainable growth of global economics and attracting much attention of experts and specialists worldwide.

The bulk of this analysis is related to three different types of literature. First, there is literature on the roles of understanding investment decisions for venture capital, including studies on proper incentive mechanism considering moral hazard problem and information asymmetry (e.g., Hellmann $[1,2]$; Casamatta [3]; Schmidt [4]; Bergemann and Hege [5]; Giat and Subramanian [6]; Wang and Zhou [7]; Agliardi and Koussis [8]; Gemson et al. [9]; Kerr and Nanda [10]).

Second, there exist literatures on the optimal funding policies under the continuous time model, which assume the value of the project is uncertain and follows a geometric Brownian motion and dealing with the decision making process in VC-projects pleads for the application of the real option approach. Dixit and Pindyck [11] answer the important questions about investment decisions and the behavior of investment spending. This new approach to investment recognizes the option value of waiting for better (but never complete) information. They develop the implications of this theory for industry dynamics and for government policy related investment. Cossin et al. [12] provide results such as timing of investments, length of duration, choices of 
liquidation levels, and conversion levels that take into account full interaction of the different features considered; [12] stresses the overall importance of a full option analysis for efficient contract negotiation and understanding. Li [13] takes a real options perspective towards venture capital staging and views the staging decision as a choice between holding the current option to invest and investing now to obtain the option to invest subsequently. $\mathrm{Li}$ also proposes that this staging decision depends on the factors that influence the value of these two options, such as competition and various sources of uncertainty. Lukas et al. [14] present a dynamic model of entrepreneurial venture financing under uncertainty based on option exercise games between EN and $\mathrm{VC}$; their novel approach combines compound option pricing with sequential noncooperative contracting, allowing us to determine whether renegotiation will improve the probability of coming to an agreement and whether to proceed with the venture.

Finally, there is extensive literature on the staged optimal funding policies under the continuous time model arguing for the application of multistage compound real options. Pennings and Sereno [15] set up a compound option approach for evaluating pharmaceutical $R \& D$ investment projects in the presence of technical and economic uncertainties. They show that both uncertainties have a positive impact on the R\&D option value. Hsu [16] models venture capital investment opportunities as real options with multiple volatilities, and the entrepreneur's incentive is assumed to maximize the probability of getting funded in the next financing round.

It is necessary to analyze the different contributions and contrasting points of view in this paper.

Most of the existing venture capital literature assumes the value of projects follows a geometric Brownian motion; hence the geometric Brownian motion could appropriately describe the process of project value, but an even more important reason is its solid mathematical basis. However, it is a puzzle in practice that there exists a big gap between the theoretical projects value derived from geometric Brownian motion and the real world projects value when unexpected major events or incidents occur. For example, several companies start the R\&D programs for the same high-tech project simultaneously; if any one of them make great progress on the project it may significantly affect the rest of the companies' $\mathrm{R} \& \mathrm{D}$ schedules and project values. As a consequence of that, a special jump-diffusion model first described by Samuelson [17] into traditional geometric Brownian motion will accurately show the innovate project valuation when unexpected major events occur.

Combining multistaging and joint contracting allows both parties to negotiate about the financing policy of stages, respectively. These methods cover an extensive distribution of VC funding in the real world. According to the data from Qing research center, venture investment market of China disclosed investment event 1103; amount totaled USD 8.245 billion in the first half year of 2015, with about 87.12 percent of multistaging investment.

Finally, the success of investment, in general, is affected by different type of uncertainty related to unexpected major events; different from any existing venture capital literature, we define $\lambda$, originating from passion distribution, as a measurable parameter for uncertainty of unexpected major events, such as major technical breakthrough or the projects competition by corporations. It is necessary to investigate the influences of different uncertainties for both the project valuation and choice of timing.

This paper proceeds as follows. In the next section, we put forward to model setup; Section 3 derives efficient outcomes using the Samuelson jump; Section 4 derives solutions of project option; Section 5 provides the numerical results and comparative-static analysis; Finally, Section 6 concludes the paper and directions for future research are proposed.

\section{Basic Setup}

We begin the analysis with a simple case of a temporal structure dividing VC-finance into two different phases. The first phase has the length of time $T_{1}$, starting from $t_{0}$ to $t_{1}$, assumed as the phase of project development and prepared for commercial phase. The second phase begins from $t_{1}$, which has no finite length of time, assumed as commercial phase, in which the project turns to product and could be traded as marketable and commercialization may commence.

To simplify the model, the project requires investment from entrepreneur and VC-investor at the beginning of each investment period $\left(I_{0}\right.$ at $t_{0}, I_{1}$ at $\left.t_{1}\right)$. We define $\gamma$ as the share of the investment project value (i.e., $I_{1 \cdot \mathrm{vc}}=\gamma I_{1}, I_{1 \cdot \mathrm{en}}=$ $\left.(1-\gamma) I_{1}\right)$. The project value, which is $V_{t}$ at time $t$, follows a geometric Brownian motion with jump-diffusion described by Samuelson.

$$
\frac{d V_{t}}{V_{t}}=(r-\delta) d t+\sigma d w_{t}+U d q_{t}
$$

where $r \in \mathbb{R}$ is the risk-free interest rate; $\delta \in \mathbb{R}$ denotes the opportunity of waiting; $\sigma$ is the constant variance parameter; $d w_{t}$ is the increment of a Wiener process; $d q_{t}$ is a Poisson process with constant intensity $\lambda>0$; if the Poisson event occurs, then the project price goes to zero. The project $V_{t}$ has two sources of uncertainty; the term $\sigma d w_{t}$ corresponds to uncertainty of risk of market, while the term $d q_{t}$ describes the uncertainty of unexpected major events. For example, we have a project of mobile phone peripheral which can easily be completely replaced, and our project will become valueless if the succedaneum idea turns to product ahead of ours.

\section{The Efficient Outcome}

In the second phase of staged financed investment project, entrepreneur chooses optimal timing of market entry and the VC-investor must provide funds determined in the contract. The solution to this optimization problem is based on Dixit and Pindyck [11] and Merton [18].

Proposition 1. Entrepreneur will invest the project under continuous time model with Samuelson jump iff the project 
value surpasses a certain critical project value threshold $V^{*}$ derived by

$$
V^{*}=\frac{\beta}{\beta-1} I_{1},
$$

which depends on the parameter $\beta$

$$
=\frac{\sigma^{2}-2(r-\delta+\lambda)+\sqrt{8 \sigma^{2}(r+\lambda)+\left[2(r-\delta+\lambda)-\sigma^{2}\right]^{2}}}{2 \sigma^{2}} .
$$

Proof. Under the equivalent martingale measure and the risk neutral pricing model, the formula of project price $V_{t}$ turns to be as follows:

$$
\frac{d V_{t}}{V_{t}}=(r-\delta-\lambda k) d t+\sigma d w_{t}+U d q_{t} .
$$

Then applying Itô’s Lemma yields

$$
\begin{aligned}
d \ln V_{t}= & \left(r-\delta-\frac{1}{2} \sigma^{2}-\lambda k\right) d t+\sigma d w_{t} \\
& +\ln (1+U) d q_{t} .
\end{aligned}
$$

We follow the jump-diffusion model described by Samuelson $[17$, p. 16, fn. 6] that if the Poisson event occurs, then the project price goes to zero. According to Dixit and Pindyck [11, ch. 5],

$$
r F d t=E[d F] .
$$

If major event does not occur,

$$
d F_{1}=\frac{\partial F}{\partial t}+\frac{1}{2} \sigma^{2} V_{t}^{2} \frac{\partial^{2} F}{\partial t^{2}} d t+\frac{\partial F}{\partial V_{t}} d V_{t}
$$

If major event occurs, then

$$
d F_{2}=F\left[(1+U) V_{t}\right]-F\left(V_{t}\right)=-F\left(V_{t}\right) .
$$

We assume formula of $F$ satisfies as $F=A V^{\beta}$, then we have

$$
\begin{aligned}
r F d t & =(1-\lambda d t)\{0 \\
& +\beta A V^{\beta-1}\left[(r-\delta-\lambda k) d t+\sigma d w_{t}\right] \\
& \left.+\frac{1}{2} \sigma^{2} V^{2} \beta(\beta-1) A V^{\beta-2}\right\}+\lambda d t\left(-F\left(V_{t}\right)\right) .
\end{aligned}
$$

$k=-1$, since price goes to zero

$$
\begin{aligned}
& \frac{1}{2} \sigma^{2} \beta(\beta-1)+\beta(r-\delta+\lambda)-(\lambda+r)=0, \\
& \beta \\
& =\frac{\sigma^{2}-2(r-\delta+\lambda)+\sqrt{8 \sigma^{2}(r+\lambda)+\left[2(r-\delta+\lambda)-\sigma^{2}\right]^{2}}}{2 \sigma^{2}}, \\
& V^{*}=\frac{\beta}{\beta-1} I_{1}, \\
& A=\frac{V^{*}-I_{1}}{\left(V^{*}\right)^{\beta}} .
\end{aligned}
$$

Optimal timing of market entry for entrepreneur is chosen when the project value surpasses $V^{*}$

$$
\begin{aligned}
& W=F, \quad V_{t}<V^{*}, \\
& W=V_{t}-I_{1}, \quad V_{t}>V^{*} .
\end{aligned}
$$

The entrepreneur will not enter the market for the reason of ensuring the benefits of shareholders (both entrepreneur and VC-investor) when the value of project is below the threshold $V^{*}$. On the contrary, holding the project out of the commercialization until the project value surpasses the threshold value is a much more intelligent strategy for the shareholders.

\section{Project Valuation with Jump-Diffusion Model}

The first phase of the investment in our analysis is the period that the entrepreneur obtains the capital funds from VCinvestor and conducts technological transfer and training to the project research and design. In consequence of that, at the first beginning of first phase, entrepreneur needs to take an investment offer including report funds needed $I_{0}$, $I_{1}$ and profit sharing schemes $\gamma_{\mathrm{VC}}$ to VC-investor. After the $\mathrm{VC}$-investor makes the decision on whether to invest the project and the negotiation about sharing schemes of funds and profit between entrepreneur and VC-investor, the entrepreneur decides on whether to start the project or not. As the reason of the assumption that profit sharing $\gamma$ is also the funds sharing in our analysis, investment value existence is for both entrepreneur and VC-investor if and only if the project option value $C_{0}$, which is the discounted expected value of the commercialization option value $W$, surpasses the first around investment $I_{0}$.

Proposition 2. Entrepreneur and VC-investor will provide funds of size $I_{0}$ at $t_{0}$ iff the project option value $C_{0}$ surpasses the first phase fund $I_{0}$, where $C_{0}$ denotes the respective value of the option to finance and is given by

$$
\begin{aligned}
C_{0}= & -V_{0} N\left(d_{1}\right)+e^{-\left(t_{1}-t_{0}\right)\left(r_{0}+\lambda\right)} I_{1} N\left(d_{2}\right) \\
& +e^{\delta} A V_{0}^{\beta} N\left(d_{3}\right), \\
d_{1}= & d_{2}+\sigma \sqrt{\left(t_{1}-t_{0}\right)} \\
= & \frac{1}{\sigma \sqrt{\left(t_{1}-t_{0}\right)}}\left[\ln \frac{V_{0}}{V^{*}}+\left(r_{0}+\frac{1}{2} \sigma^{2}+\lambda\right)\right], \\
d_{2}= & \frac{1}{\sigma \sqrt{\left(t_{1}-t_{0}\right)}}\left[\ln \frac{V_{0}}{V^{*}}+\left(r_{0}-\frac{1}{2} \sigma^{2}+\lambda\right)\right], \\
d_{3}= & \frac{\beta \ln \left(V^{*} / V_{0}\right)-r t-(1 / 2) \sigma^{2} \beta^{2} t}{\sigma \beta \sqrt{\left(t_{1}-t_{0}\right)}} .
\end{aligned}
$$


Proof. The option value to finance $C_{0}$ is the discount expected value of the second phase:

$$
\begin{aligned}
C_{0}= & e^{-\lambda\left(t_{1}-t_{0}\right)} e^{-(r-\delta)\left(t_{1}-t_{0}\right)} \widetilde{E}(W), \\
C_{0}= & e^{-\lambda\left(t_{1}-t_{0}\right)} \widetilde{E}\left[e^{-(r-\delta)\left(t_{1}-t_{0}\right)} F\right] \\
& +e^{-\lambda\left(t_{1}-t_{0}\right)} \widetilde{E}\left[e^{-(r-\delta) t}\left(V_{1}-I_{1}\right)\right] .
\end{aligned}
$$

Let $(r-\delta)=r_{0}$; then it yields

$$
\begin{aligned}
e^{-\lambda\left(t_{1}-t_{0}\right)} \widetilde{E} & {\left[e^{-r_{0}\left(t_{1}-t_{0}\right)}\left(V_{1}-I_{1}\right)\right] } \\
= & e^{-\lambda\left(t_{1}-t_{0}\right)} \widetilde{E}\left[e ^ { - r _ { 0 } ( t _ { 1 } - t _ { 0 } ) } \left(V_{0} e^{-\sigma \sqrt{\left(t_{1}-t_{0}\right)} y+\left(r_{0}+\lambda-(1 / 2) \sigma^{2}\right)\left(t_{1}-t_{0}\right)}\right.\right. \\
- & \left.\left.I_{1}\right)\right]=e^{-\lambda\left(t_{1}-t_{0}\right)} \frac{1}{\sqrt{2 \pi}} \\
& \cdot \int_{V^{*}}^{+\infty}\left[e^{-r_{0}\left(t_{1}-t_{0}\right)}\left(V_{0} e^{-\sigma \sqrt{\left(t_{1}-t_{0}\right)} y+\left(r_{0}+\lambda-(1 / 2) \sigma^{2}\right)\left(t_{1}-t_{0}\right)}-I_{1}\right)\right] \\
& \cdot e^{-(1 / 2) y^{2}} d y,
\end{aligned}
$$$$
y<d 2=\frac{1}{\sigma \sqrt{\left(t_{1}-t_{0}\right)}}\left[\ln \frac{V_{0}}{V^{*}}+\left(r_{0}-\frac{1}{2} \sigma^{2}+\lambda\right)\right] .
$$

As the reason of $V_{0} e^{-\sigma \sqrt{\left(t_{1}-t_{0}\right)} Y+\left(r_{0}+\lambda-(1 / 2) \sigma^{2}\right)\left(t_{1}-t_{0}\right)}-I_{1} \geq 0$, then we have

$$
\begin{aligned}
C_{0}^{1} & =-e^{-\lambda\left(t_{1}-t_{0}\right)} \frac{1}{\sqrt{2 \pi}} \\
& \cdot \int_{-\infty}^{d_{2}}\left[e ^ { - r _ { 0 } ( t _ { 1 } - t _ { 0 } ) } \left(V_{0} e^{-\sigma \sqrt{\left(t_{1}-t_{0}\right)} y+\left(r_{0}+\lambda-(1 / 2) \sigma^{2}\right)\left(t_{1}-t_{0}\right)}\right.\right. \\
& \left.\left.-I_{1}\right)\right] e^{-(1 / 2) y^{2}} d y=-\frac{1}{\sqrt{2 \pi}} \\
& \cdot \int_{-\infty}^{d_{2}} V_{0} e^{-\sigma \sqrt{\left(t_{1}-t_{0}\right)} y-(1 / 2) \sigma^{2}\left(t_{1}-t_{0}\right)-(1 / 2) y^{2}} d y+\frac{1}{\sqrt{2 \pi}} \\
& \cdot \int_{-\infty}^{d_{2}} e^{-\left(r_{0}+\lambda\right)\left(t_{1}-t_{0}\right)} I_{1} e^{-(1 / 2) y^{2}} d y=-V_{0} N\left(d_{1}\right) \\
& +e^{-\left(t_{1}-t_{0}\right)\left(r_{0}+\lambda\right)} I_{1} N\left(d_{2}\right),
\end{aligned}
$$

where

$$
\begin{aligned}
d_{1} & =d_{2}+\sigma \sqrt{\left(t_{1}-t_{0}\right)} \\
& =\frac{1}{\sigma \sqrt{\left(t_{1}-t_{0}\right)}}\left[\ln \frac{V_{0}}{V^{*}}+\left(r_{0}+\frac{1}{2} \sigma^{2}+\lambda\right)\right]
\end{aligned}
$$

Consider the part $e^{-\lambda\left(t_{1}-t_{0}\right)} \widetilde{E}\left[e^{-(r-\delta)\left(t_{1}-t_{0}\right)} F\right]$. Let $g=V^{\beta}$; then applying Itô's Lemma yields

$$
\begin{aligned}
d g= & \frac{\partial g}{\partial V} d V+\frac{1}{2} \frac{\partial^{2} g}{\partial V^{2}} d V^{2} \\
= & {\left[\frac{1}{2} \sigma^{2} \beta(\beta-1)+\beta(r-\delta+\lambda)\right] g d t } \\
& +\beta \sigma g d W_{t}+\beta g U d q_{t},
\end{aligned}
$$

$$
\left(\frac{d V}{V}\right)^{\beta}=(r+\lambda) d t+\beta \sigma d W_{t}+\beta U d q_{t} .
$$

which is a process of geometric Brownian motion with jumpdiffusion described by Samuelson.

$$
\begin{aligned}
& e^{-\lambda\left(t_{1}-t_{0}\right)} \widetilde{E}\left[e^{-(r-\delta)\left(t_{1}-t_{0}\right)} F\right] \\
& =e^{-(\lambda+r)} e^{\delta} A \int_{-\infty}^{V^{*}} V_{0}^{\beta} e^{(r+\lambda)\left(t_{1}-t_{0}\right)} e^{y} \\
& \cdot \frac{1}{\sigma \beta \sqrt{2 \pi\left(t_{1}-t_{0}\right)}} e^{-\left(y+(1 / 2) \beta^{2} \sigma^{2}\left(t_{1}-t_{0}\right)\right)^{2} / 2 \beta^{2} \sigma^{2}\left(t_{1}-t_{0}\right)} d y \\
& =e^{\delta} A \int_{-\infty}^{\beta \ln \left(V^{*} / V_{0}\right)-r\left(t_{1}-t_{0}\right)} V_{0}^{\beta} \\
& \cdot \frac{1}{\sigma \beta \sqrt{2 \pi\left(t_{1}-t_{0}\right)}} e^{-(1 / 2)\left(\left(y-(1 / 2) \sigma^{2} \beta^{2}\left(t_{1}-t_{0}\right)\right)^{2} / \sigma^{2} \beta^{2}\left(t_{1}-t_{0}\right)\right)} d y,
\end{aligned}
$$

where $y \sim N\left((1 / 2) \beta^{2} \sigma^{2}\left(t_{1}-t_{0}\right), \beta^{2} \sigma^{2}\left(t_{1}-t_{0}\right)\right)$. Let $x=(y-$ $\left.(1 / 2) \sigma^{2} \beta^{2}\left(t_{1}-t_{0}\right)\right) / \sigma \beta \sqrt{\left(t_{1}-t_{0}\right)}$; then we got

$$
\begin{aligned}
& e^{-\lambda\left(t_{1}-t_{0}\right)} \widetilde{E}\left[e^{-(r-\delta)\left(t_{1}-t_{0}\right)} F\right] \\
& =e^{\delta} A \int_{-\infty}^{\left(\beta \ln \left(V^{*} / V_{0}\right)-r\left(t_{1}-t_{0}\right)-(1 / 2) \sigma^{2} \beta^{2}\left(t_{1}-t_{0}\right)\right) / \sigma \beta \sqrt{\left(t_{1}-t_{0}\right)}} V_{0}^{\beta} \\
& \quad \cdot \frac{1}{\sqrt{2 \pi}} e^{-(1 / 2) x^{2}} d x=e^{\delta} A V_{0}^{\beta} N\left(d_{3}\right) d_{3} \\
& =\frac{\beta \ln \left(V^{*} / V_{0}\right)-r\left(t_{1}-t_{0}\right)-(1 / 2) \sigma^{2} \beta^{2}\left(t_{1}-t_{0}\right)}{\sigma \beta \sqrt{\left(t_{1}-t_{0}\right)}} .
\end{aligned}
$$

Finally we have

$$
\begin{aligned}
& C_{0} \\
& \quad=-V_{0} N\left(d_{1}\right)+e^{-\left(t_{1}-t_{0}\right)\left(r_{0}+\lambda\right)} I_{1} N\left(d_{2}\right)
\end{aligned}
$$




$$
\begin{aligned}
& +e^{\delta} A V_{0}^{\beta} N\left(d_{3}\right), \\
d_{1}= & d_{2}+\sigma \sqrt{\left(t_{1}-t_{0}\right)} \\
= & \frac{1}{\sigma \sqrt{\left(t_{1}-t_{0}\right)}}\left[\ln \frac{V_{0}}{V^{*}}+\left(r_{0}+\frac{1}{2} \sigma^{2}+\lambda\right)\right], \\
d_{2}= & \frac{1}{\sigma \sqrt{\left(t_{1}-t_{0}\right)}}\left[\ln \frac{V_{0}}{V^{*}}+\left(r_{0}-\frac{1}{2} \sigma^{2}+\lambda\right)\right], \\
d_{3} & \beta \ln \left(V^{*} / V_{0}\right)-\left(t_{1}-t_{0}\right) r-(1 / 2) \sigma^{2} \beta^{2}\left(t_{1}-t_{0}\right) \\
= & \frac{\sigma \beta \sqrt{\left(t_{1}-t_{0}\right)}}{} .
\end{aligned}
$$

As alluded to earlier Proposition 2, $C_{0}$ is the option value of innovative project with parameter $I_{1}$, meaning that determining optimal decisions is solved by starting from the commercial phase, which needs us to determine second rounds investment funds $I_{1}$ first and then determine the first rounds investment funds $I_{0}$.

\section{Comparative-Static Analysis and Numerical Results}

The purpose of this section is to investigate the relationship between the option price of project $C_{0}$, the funding threshold $V^{*}$, and uncertainty of major events or economics. Furthermore, we also analyze the relationship of $V_{0}, I_{1}$, and option price $C_{0}$; particularly, we find the optimal value of $I_{1}, V_{0}$ for fixed parameters given by thorough numerical method.

5.1. Comparative-Static Analysis. Figure 1 depicts the critical threshold as a function of the economic uncertainty $\sigma$. The result indicates that economic uncertainty and major events uncertainty both increase the funding threshold $V^{*}$.

Figure 2 depicts the critical threshold as a function of the major events uncertainty $\lambda$. Result indicates that major events uncertainty increases the funding threshold $V^{*}$ obviously.

Conclusion 3. The funding threshold $V^{*}$ is positively affected by both economic uncertainty $\sigma$ and major events uncertainty $\lambda$.

Both sources of uncertainties will increase the funding threshold, meaning the optimal timing into commercial is delayed and hence depresses investment, because the more the uncertainties the firm faces, the higher the project value needed to compensate for the risk.

Figure 3 depicts the option price $C_{0}$ as a function of the economic uncertainty $\sigma$ (a) or major events uncertainty $\lambda$. The result indicates that both kinds of uncertainty increase the option price $C_{0}$ and indicate that as the uncertainty increases, financing the venture will become more attractive.

Figure 4 depicts the option price $C_{0}$ as a function of economic uncertainty $\sigma$. The results show that for the given parameter values a positive relation prevails with or

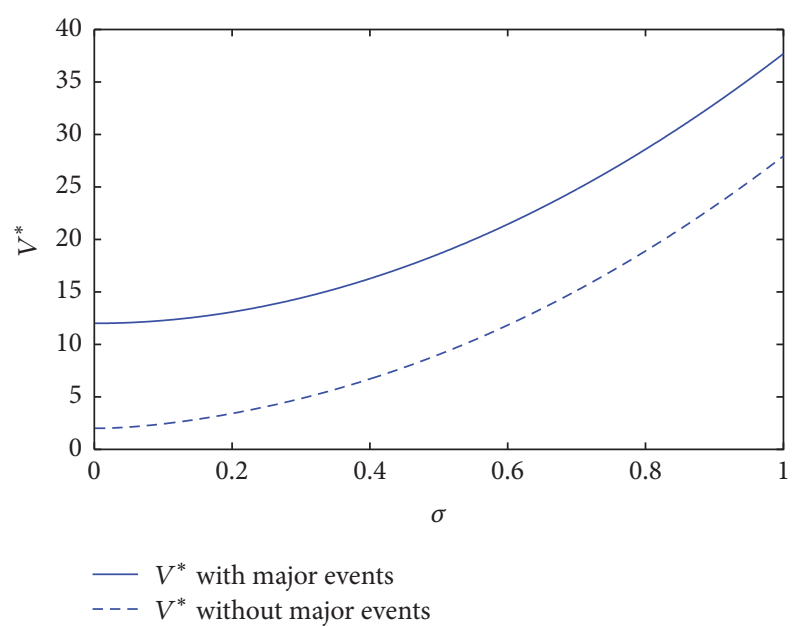

FIgURE 1: The relationship between the funding threshold $V^{*}$ and market uncertainty $\sigma$ with (solid line) or without (dashed line) major events. Solid line: $\lambda=0.2 ; r=0.04 ; \delta=0.02 ; I_{1}=1$. Dashed line: $\lambda=$ $0 ; r=0.04 ; \delta=0.02 ; I_{1}=1$.

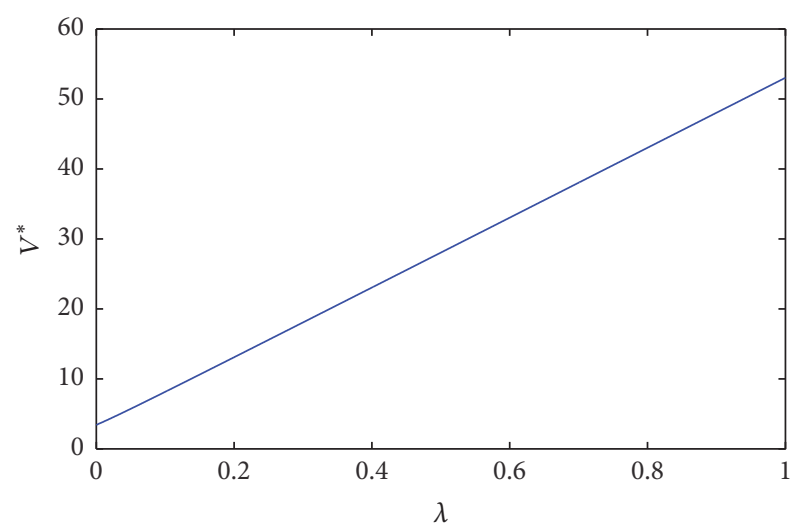

FIgUre 2: The relationship between the funding threshold $V^{*}$ and major events uncertainty $\lambda . \sigma=0.2 ; r=0.04 ; \delta=0.02 ; I_{1}=1$.

without major events uncertainty $\lambda$. Figure 4 also highlights that the option value with major events uncertainty $\lambda$ is larger than without, because the higher option value makes compensation for the larger uncertainties.

Conclusion 4. The option value of project $C_{0}$ is positively affected by both economic uncertainty $\sigma$ and major events uncertainty $\lambda$.

Conclusion 5. The option value of project $C_{0}$ with unexpected major events is larger than without.

Hence an increase in uncertainty enhances the option price $C_{0}$ and indicates that higher anticipated-income of the project comes with larger uncertainties, which is consistent with real world economics. The option value with major events uncertainty $\lambda$ is larger than without as the reason of the higher option value makes compensation for the larger uncertainties. 


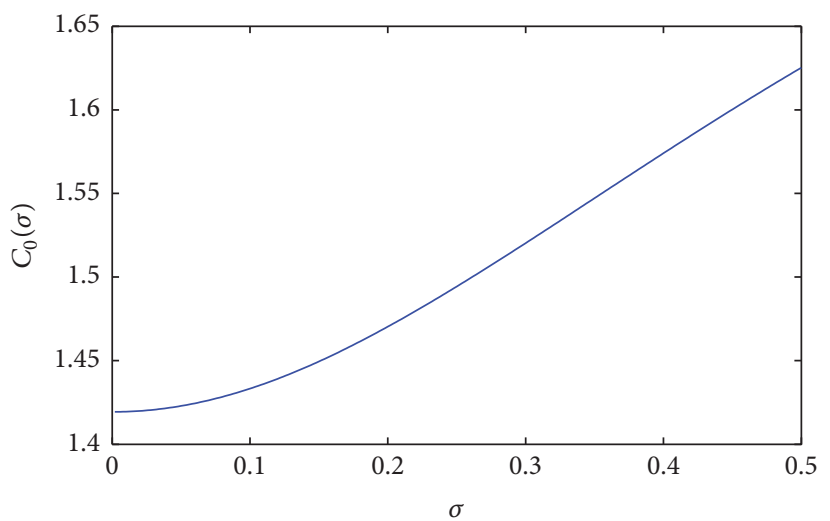

(a)

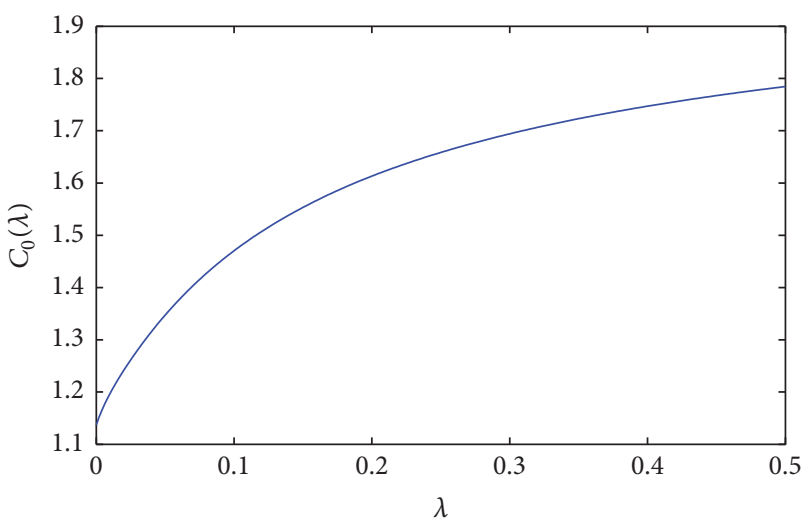

(b)

FIGURE 3: The relationship between the option price $C_{0}$ and market uncertainty $\sigma(\mathrm{a})$ or major events uncertainty $\lambda(\mathrm{b})$. Figure 3(a): $\lambda=0.1$; $r=0.04 ; \delta=0.02 ; I_{1}=1 ;\left(t_{1}-t_{0}\right)=1 ; V_{0}=2$. Figure $3(\mathrm{~b}): \sigma=0.1 ; r=0.04 ; \delta=0.02 ; I_{1}=1 ;\left(t_{1}-t_{0}\right)=1 ; V_{0}=2$.

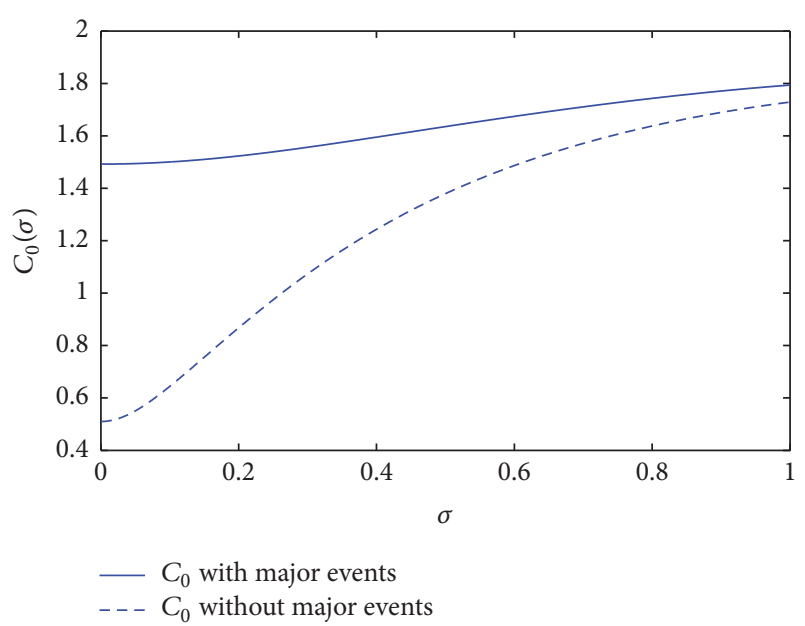

Figure 4: The relationship between the option price $C_{0}$ and market uncertainty $\sigma$ with (solid line) or without (dashed line) major events uncertainties $\lambda$. Solid line: $\lambda=0.2 ; r=0.04 ; \delta=0.02 ; V_{0}=2 ; t_{1}-t_{0}=$ $1 ; I_{1}=2$. Dashed line: $\lambda=0 ; r=0.04 ; \delta=0.02 ; V_{0}=2 ; t_{1}-t_{0}=1 ; I_{1}$ $=2$.

Figure 5 depicts the option price $C_{0}$ as a function of the second-phase investment funds $I_{1}$. With the increase of second-phase investment amounts, $C_{0}$ increases sharply at first and then decreases and $C_{0}$ max exists as the change of $I_{1}$ which we can find out by numerical method.

Conclusion 6. When the parameters are given, for different initial project value $V_{0}$, there always exists an optimal investment of second rounds $I_{1}$, leading to the option value of project $C_{0}$ which reaches its maximum.

The project has no application value without investment of commercialization. As the second-phase investment amounts increase and profit gains of the project cover the costs and achieve the maximum value of project option $C_{0}$ $\max$. After the $C_{0}$ max point, the increase of investment $I_{1}$ just increases the cost of project and the project value threshold $V^{*}$.

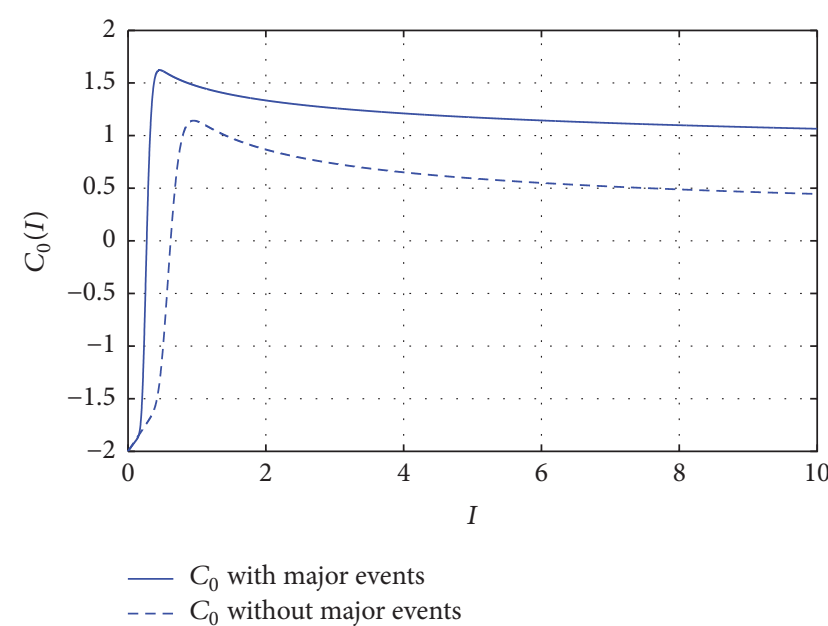

FIgURE 5: The relationship between the option price $C_{0}$ and the second phases fund of size $I_{1}$ with (solid line) or without (dashed line) major events uncertainties $\lambda$. Solid line: $\lambda=0.1 ; r=0.04 ; \delta=$ $0.02 ; V_{0}=2 ; t_{1}-t_{0}=1$. Dashed line: $\lambda=0 ; r=0.04 ; \delta=0.02 ; V_{0}=$ $2 ; t_{1}-t_{0}=1$.

Figure 6 depicts the option price $C_{0}$ as a function of the project value $V_{0}$. With the increase of project value $C_{0}$ increases sharply at first and then decreases and $C_{0}$ max exists as the change of $V_{0}$ which we can find out by numerical method. The reason of $C_{0}$ 's variety track is analyzed as follows: for the fixed $I_{1}$, second-round investment-to-project ratio, which causes an optimal ratio, decreases with the increase of project $V_{0}$. The ratio maximizes the option value $C_{0}$ when it reaches the optimal point.

Conclusion 7. When the parameters are given, for different fixed size of investment funds $I_{1}$, there always exists an optimal initial project value $V_{0}$, leading to the option value of project $C_{0}$ which reaches its maximum.

The application of Conclusion 7 is widely distributed in the real word investment activities. When the total size of 


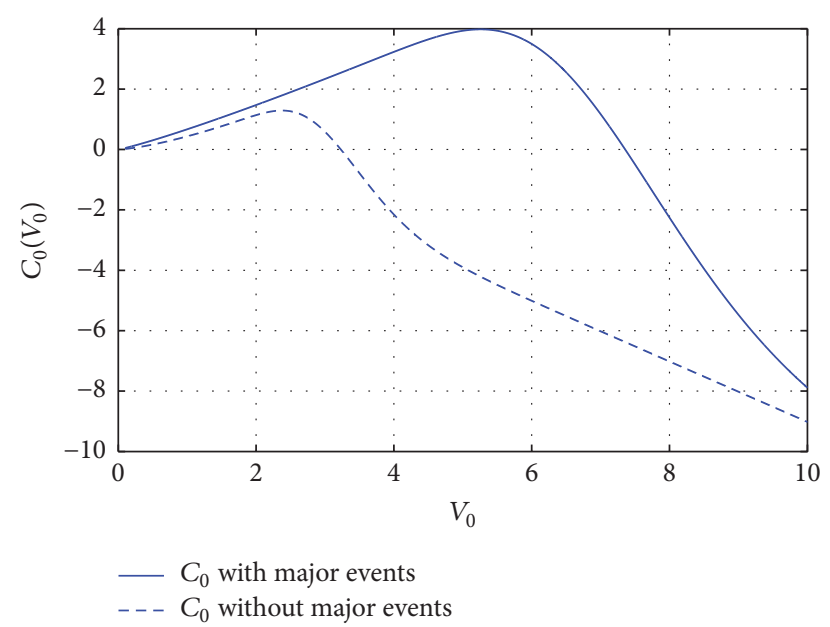

FIgURE 6: The relationship between the option price $C_{0}$ and the initial project value $V_{0}$ with (solid line) or without (dashed line) major events uncertainties $\lambda$. Solid line: $\lambda=0.1 ; r=0.04 ; \delta=0.02$; $t_{1}-t_{0}=1 ; I_{1}=2$. Dashed line: $\lambda=0 ; r=0.04 ; \delta=0.02 ; t_{1}-t_{0}=1$; $I_{1}=2$.

TABle 1: Depicting the maximal $C_{0}$ considering major events uncertainty $\lambda$ and corresponding $I_{1}$ with different $V_{0}$. The used parameters are $\lambda=0.1 ; r=0.04 ; \delta=0.02 ; \sigma=0.2 ;\left(t_{1}-t_{0}\right)=1$.

\begin{tabular}{lccc}
\hline$V_{0}$ & $C_{0} \max$ & $I_{1} \max$ & $I_{1} / C_{0} \max$ \\
\hline 1 & 0.8112 & 0.2320 & 0.2860 \\
2 & 1.6225 & 0.4630 & 0.2854 \\
3 & 2.4337 & 0.6930 & 0.2847 \\
4 & 3.2450 & 0.9240 & 0.2847 \\
5 & 4.0562 & 1.1550 & 0.2847 \\
6 & 4.8675 & 1.3860 & 0.2847 \\
\hline
\end{tabular}

funds is fixed, overactive or passive investment plan cannot lead to the optimal ROI; the only way to get the reasonable return is to invest the project with proper amount associated with funds size.

5.2. Numerical Results. In this subsection, we provide some numerical results on option value of the project with different fixed conditions. In order to implement the maximum of the project option value $C_{0} \max$ and the corresponding conditions we use Matlab programming.

The simulation of Tables 1 and 2 shows that the model is highly reliable with or without major events uncertainty; it offers very important applicable values in real world VCinvestment. In practice, VC-investor and entrepreneur could determine the optimal funds size of commercial phase to maximize the option value $C_{0}$ for different initial project value $V_{0}$ and improve the efficiency of investment activities for finite investment funds.

The simulation of Tables 3 and 4 shows that the model is highly reliable with or without major events uncertainty; it also offers very important applicable values in real world VC-investment. Particularly, VC-investor could choose the most profitable project with optimal initial project value $V_{0}$
TABLE 2: Depicting the maximal $C_{0}$ without considering major events uncertainty $\lambda$ and corresponding $I_{1}$ with different $V_{0}$. The used parameters are $\lambda=0 ; r=0.04 ; \delta=0.02 ; \sigma=0.2 ;\left(t_{1}-t_{0}\right)=$ 1.

\begin{tabular}{lccc}
\hline$V_{0}$ & $C_{0} \max$ & $I_{1} \max$ & $I_{1} / C_{0} \max$ \\
\hline 1 & 0.5711 & 0.4770 & 0.8352 \\
2 & 1.1423 & 0.9530 & 0.8343 \\
3 & 1.7134 & 1.4280 & 0.8334 \\
4 & 2.2845 & 1.9040 & 0.8334 \\
5 & 2.8557 & 2.3800 & 0.8334 \\
6 & 3.4268 & 2.8560 & 0.8334 \\
\hline
\end{tabular}

TABle 3: Depicting the maximal $C_{0}$ considering major events uncertainty $\lambda$ and corresponding $V_{0}$ with different $I_{1}$. The used parameters are $\lambda=0.1 ; r=0.04 ; \delta=0.02 ; \sigma=0.2 ;\left(t_{1}-t_{0}\right)=1$.

\begin{tabular}{lccc}
\hline$I_{1}$ & $C_{0} \max$ & $V_{0} \max$ & $C_{0} / V_{0} \max$ \\
\hline 1 & 3.9769 & 5.1620 & 0.7704 \\
2 & 7.9537 & 10.4220 & 0.7632 \\
3 & 11.9306 & 15.6830 & 0.7607 \\
4 & 15.9075 & 20.9440 & 0.7595 \\
5 & 19.8844 & 26.2040 & 0.7588 \\
6 & 23.8612 & 31.4650 & 0.7583 \\
\hline
\end{tabular}

TABle 4: Depicting the maximal $C_{0}$ without considering major events uncertainty $\lambda$ and corresponding $V_{0}$ with different $I_{1}$. The used parameters are $\lambda=0 ; r=0.04 ; \delta=0.02 ; \sigma=0.2 ;\left(t_{1}-t_{0}\right)=$ 1 .

\begin{tabular}{lccc}
\hline$I_{1}$ & $C_{0} \max$ & $V_{0} \max$ & $C_{0} / V_{0} \max$ \\
\hline 1 & 1.2894 & 2.2770 & 0.5663 \\
2 & 2.5788 & 4.6530 & 0.5542 \\
3 & 3.8682 & 7.0300 & 0.5502 \\
4 & 5.1576 & 9.4060 & 0.5483 \\
5 & 6.4770 & 11.7820 & 0.5472 \\
6 & 7.7364 & 14.1580 & 0.5464 \\
\hline
\end{tabular}

for limited funds size, to improve the efficiency of investment activities.

\section{Conclusion}

In this paper, a framework for valuation of the project investment value considering unexpected major events in order to analyze the investment decision of VC-investors and entrepreneurs has been developed and explained.

We use Samuelson jump-diffusion model to adopt the process of project investment because major unexpected events occur in the real world, such as uncertainty of competition or technical breakthrough. We use the method of Dixit and Pindyck to determine the second-phase investment threshold $V^{*}$ first. Then we obtain the formula of project option value $C_{0}$ under the equivalent martingale measure and the risk neutral pricing model, considering jump-diffusion. We have analyzed the relationship between option value $C_{0}$ and comparative-static including major events uncertainty $\lambda$ 
and economic uncertainty $\sigma$, indicating that as both sources of uncertainties increase, financing the venture will become more attractive to both the entrepreneur and VC-investor. Analysis also shows the relationship of $V_{0}, I_{1}$, and $C_{0}$ by comparative-analysis and numerical simulation using Matlab, for fixed parameters given. Results show that this model is highly reliable with or without major event uncertainty and there exists an optimal ratio of second-round fundsto-project value. It also offers very important applicable values in real world VC-investment which may help VCinvestors in the real word make strategies for optimal funding policies. This framework can be used to investigate the project option value when considering unexpected major events and furthermore, this framework can help VC-investors choose the most profitable projects with optimal initial project value $V_{0}$ for limited funds size, or to determine the optimal funds size of commercial phase to maximize the option value $C_{0}$ for different initial project value $V_{0}$, to improve the efficiency of investment activities.

The framework developed here may be extended further by relaxing some of the model's initial limiting assumptions. For example, more than one party could be allowed to divert value from the project. Furthermore, a more extensive analysis of the moral hazard problem could follow from this framework.

\section{Conflicts of Interest}

The authors declare that they have no conflicts of interest.

\section{Acknowledgments}

The work on this paper was partially supported by Applied Basic Research Programs of Sichuan Province Science and Technology Department (2016JY0133), the National Natural Science Foundation of China (no. 71671142), the Humanities and Social Science Project of Ministry of Education of China (14XJCZH001), and Social Science Planning Project of Sichuan Province (SC14A030).

\section{References}

[1] T. Hellmann, "The allocation of control rights in venture capital contracts," RAND Journal of Economics, vol. 29, no. 1, pp. 57-76, 1998.

[2] T. Hellmann, "IPOs, acquisitions, and the use of convertible securities in venture capital," Journal of Financial Economics, vol. 81, no. 3, pp. 649-679, 2006.

[3] C. Casamatta, "Financing and advising: optimal financial contracts with venture capitalists," Journal of Finance, vol. 58, no. 5, pp. 2059-2085, 2003.

[4] K. M. Schmidt, "The economics of covenants as a means of efficient creditor protection," European Business Organization Law Review, vol. 7, no. 1, pp. 89-94, 2006.

[5] D. Bergemann and U. Hege, "Venture capital financing, moral hazard, and learning," Journal of Banking and Finance, vol. 22, no. 6-8, pp. 703-735, 1998.

[6] Y. Giat and A. Subramanian, "Dynamic contracting under imperfect public information and asymmetric beliefs," Journal of Economic Dynamics and Control, vol. 37, no. 12, pp. 2833-2861, 2013.
[7] S. Wang and H. Zhou, "Staged financing in venture capital: Moral hazard and risks," Journal of Corporate Finance, vol. 10, no. 1, pp. 131-155, 2004.

[8] E. Agliardi and N. Koussis, "Optimal capital structure and the impact of time-to-build," Finance Research Letters, vol. 10, no. 3, pp. 124-130, 2013.

[9] J. Gemson, Annamalai, and T. Rajan, "A new perspective on private equity stage financing: evidence from investments in infrastructure," Venture Capital, vol. 17, no. 4, pp. 299-325, 2015.

[10] W. R. Kerr and R. Nanda, "Financing innovation," Annual Review of Financial Economics, vol. 7, pp. 445-462, 2015.

[11] A. K. Dixit and R. S. Pindyck, Investment under Uncertainty, Princeton University Press, Princeton, NJ, USA, 1994.

[12] D. Cossin, B. Leleux, and E. Saliasi, "Venture investment contracts as baskets of real options," Journal of Financial Transformation, vol. 13, pp. 93-102, 2005.

[13] Y. Li, "Duration analysis of venture capital staging: a real options perspective," Journal of Business Venturing, vol. 23, no. 5, pp. 497-512, 2008.

[14] E. Lukas, S. Mölls, and A. Welling, "Venture capital, staged financing and optimal funding policies under uncertainty," European Journal of Operational Research, vol. 250, no. 1, pp. 305-313, 2016.

[15] E. Pennings and L. Sereno, "Evaluating pharmaceutical R\&D under technical and economic uncertainty," European Journal of Operational Research, vol. 212, no. 2, pp. 374-385, 2011.

[16] Y.-W. Hsu, "Staging of venture capital investment: a real options analysis," Small Business Economics, vol. 35, no. 3, pp. 265-281, 2010.

[17] P. A. Samuelson, "Mathematics of speculative price," SIAM Review, vol. 15, pp. 1-42, 1973.

[18] R. C. Merton, "Option pricing when underlying stock returns are discontinuous," Journal of Financial Economics, vol. 3, no. 1-2, pp. 125-144, 1976. 


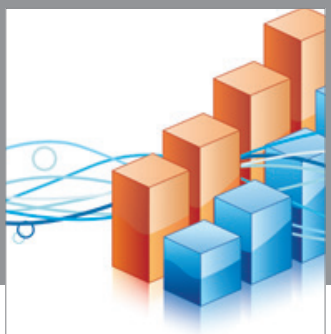

Advances in

Operations Research

vatem alat4

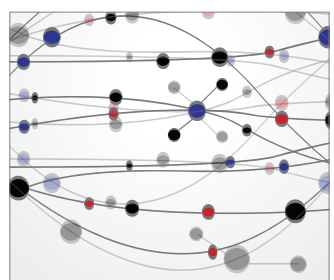

\section{The Scientific} World Journal
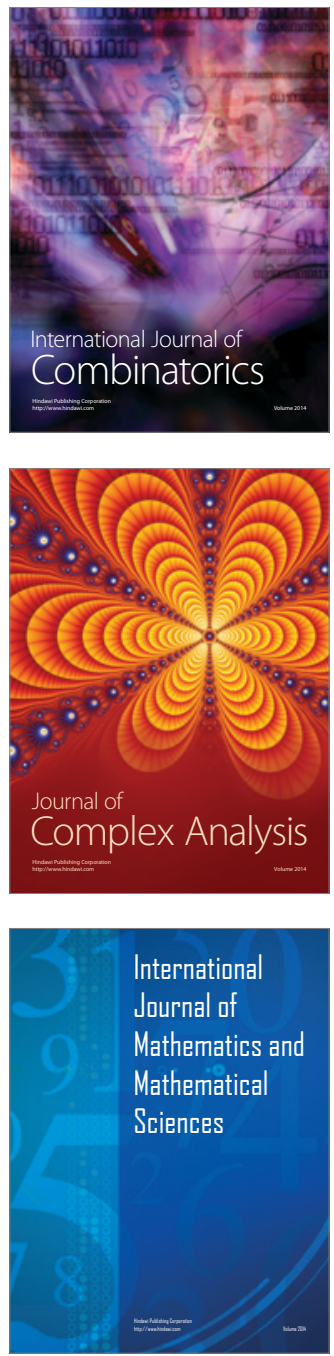
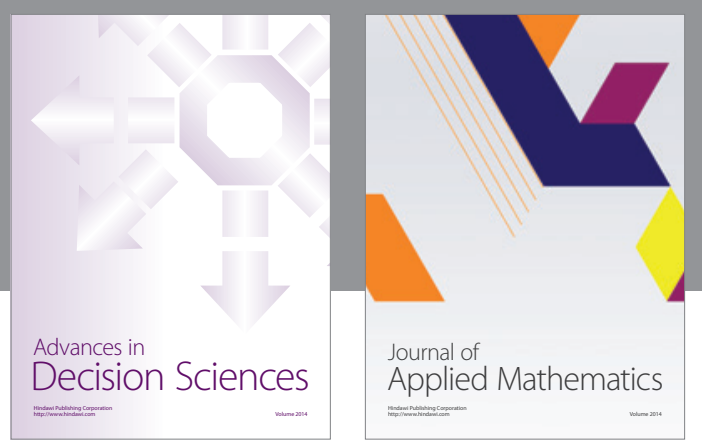

Algebra

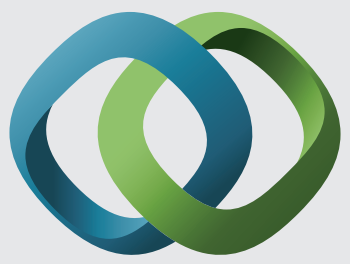

\section{Hindawi}

Submit your manuscripts at

https://www.hindawi.com
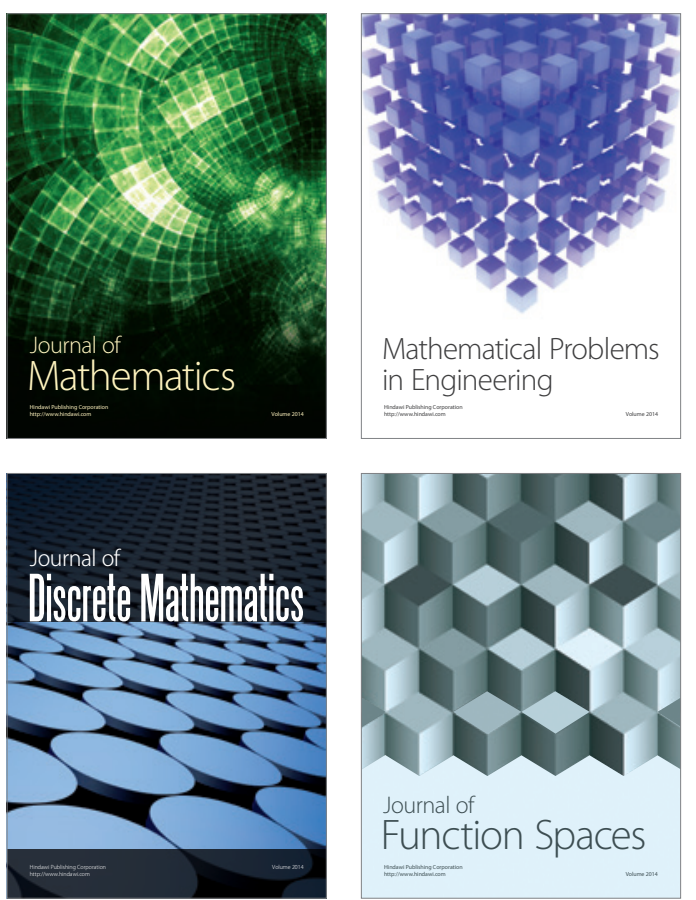

Mathematical Problems in Engineering
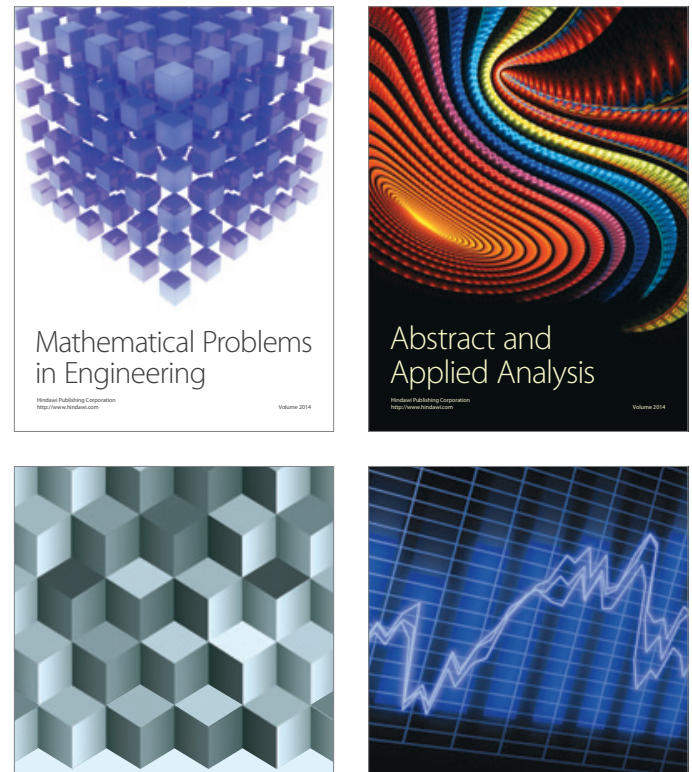

Journal of

Function Spaces

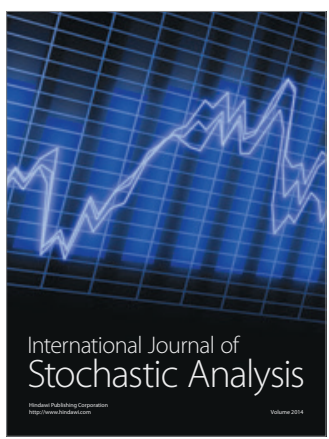

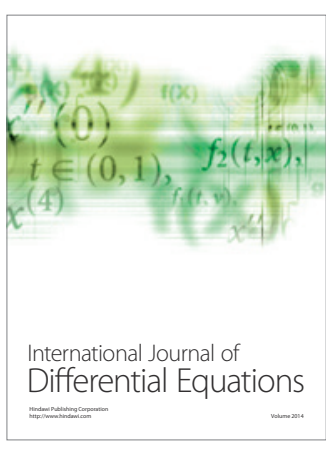
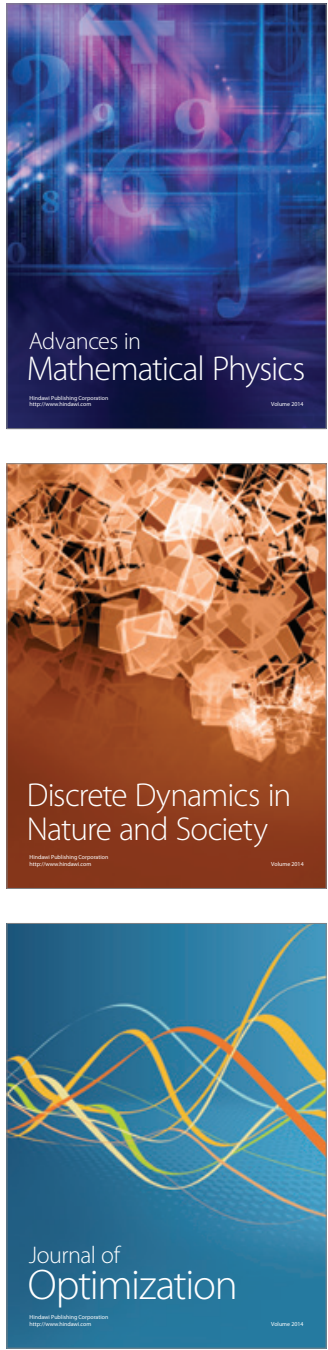